\title{
VOLUNTAD DE PODER Y HERMENÉUTICA: RASGOS FUNDAMENTALES DEL SER HUMANO NIETZSCHEANO
}

\author{
WILL TO POWER AND HERMENEUTICS: \\ FUNDAMENTAL FEATURES OF THE NIETZSCHEAN \\ HUMAN BEING
}

Pablo Frontela Asensio $a^{*}$

Fechas de recepción y aceptación: 15 de noviembre de 2019 y 29 de abril de 2020

Resumen: Se pretende ofrecer claves para presentar y comprender la estructura antropológica del sujeto nietzscheano en códigos hermenéuticos. Para ello se utilizará vehicularmente la idea de la voluntad de poder, que se desplegará a lo largo de distintos hitos de la filosofía del autor. Se rastrearán elementos fundamentales del pensamiento de Nietzsche con el fin de mostrar la coherencia de la unidad conceptual de términos aparentemente distantes como los de "devenir", "genealogía", "cuerpo" o "ser", articulados desde la condición perspectivista a la que aboca la original obra de Nietzsche. La integración sintética de los mencionados términos se apoyará, también, en la experiencia radical del nihilismo decimonónico, ofreciendo finalmente un original criterio de verdad cuya ontología respeta tanto la precariedad de la existencia humana como la indigencia de un tiempo privado de sentido último. Tras el diagnóstico de la sintomatología epocal y de la integración del hombre en tal espacio asignificativo y horizonte perspectivista se ofrecerán algunas tentativas de existencia que respeten la peculiaridad hermenéutica del hombre nietzscheano. Teniendo siempre por límite la propia vida efectiva.

\footnotetext{
${ }^{\text {a }}$ Facultad de Ciencias Sociales y Humanidades. Universidad Internacional de la Rioja (UNIR).

${ }^{*}$ Correspondencia: Pablo Fontanela Asencio. Calle Estrada, 9, 4. ${ }^{\circ}$ I. 34002 Palencia. España.

E-mail: pablo.frontela@unir.net
} 
Palabras clave: cuerpo, hermenéutica, mundo verdadero, perspectiva, ser, trágico, valor, verdad, voluntad de poder.

Abstract: It is intended to offer some clues to both introduce and understand the anthropological structure of the Nietzschean subject in hermeneutical codes. In order to do so, it shall be vehicularly used the idea of the will to power, which is to be displayed along different milestones of the author's philosophy. Fundamental elements of Nietzsche's thought will be traced so as to show the coherence of the conceptual unity of seemingly distant terms such as "becoming", "genealogy", "body", or "being", articulated from the perspectivist condition to which leads the original work of Nietzsche. The synthetic integration of the aforementioned terms will also be based on the radical experience of nineteenth-century nihilism, to finally offer an original criterion of truth whose ontology respects both the precariousness of human existence and the destitution of a time deprived of ultimate meaning. After the diagnosis of this epochal symptomatology and the integration of man into such a meaningless space and perspectivist horizon, it will be offered some attempts of existence that also respect the hermeneutical peculiarity of the Nietzschean man by having the actual effective life as a limit.

Keywords: being, body, hermeneutics, perspective, reliable world, tragic, truth, value, will to power.

\section{$\S 1$. Hacia UnA VERDAD DEVINIENTE}

La lectura de Nietzsche es una fuente inagotable de perspectivas y de meandros, muchos de ellos todavía por explorar. Sin embargo, el motivo que ocupa este artículo es menos una hipótesis o una tentativa de investigación que un tópico ya consolidado y con suficientes recursos para argumentar en su favor: la estructura hermenéutica sobre la que se vertebra el corpus del autor. El procedimiento genealógico de Nietzsche puso de manifiesto que el proceso de construcción de la verdad se presenta deviniente, por contraposición con el ser estático de la propedéutica metafísica, a lo largo de una apropiación perpetua de significación y "valorización”. Una constante que permitiría superar las conclusiones nihilistas que algunos exégetas extrajeron de la obra de Nietzsche. 
Si bien es cierto que el filósofo alemán no pertenece propiamente a la tradición hermenéutica (Grondin, 2009), no puede negarse la ascendencia de tal condición en el método genealógico, la cual facilitaría un acercamiento a la cuestión de la verdad, tanto tradicional como contemporánea. La estrategia genealógica nietzscheana introduce la cuestión de la verdad en un horizonte de atribución de significado perspectivista.

El perspectivismo se nutre del mencionado dinamismo de una noción de verdad opuesta conceptualmente al logicismo que durante las centurias modernas había acabado por colonizar el horizonte de las conciencias ya en el siglo XIX. A través de esta experiencia de reconversión de la verdad la filosofía de Nietzsche logra rebasar el dominio epistémico, y hace de esta una cuestión existencial que destaca el protagonismo de la acción creadora del sujeto. Frente a la racionalización epistémica de la razón, Nietzsche radica la experiencia de apropiación de significado de la verdad en el propio sujeto, perspectiva, contenido y continente de sentido.

\subsection{El origen ficticio del valor de la verdad}

Desde su modus genealógico Nietzsche (2007b: 25) advierte de que "las verdades son ilusiones de las que se ha olvidado que lo son"; la verdad es entonces una invención que hunde sus raíces en el deseo, en la necesidad de una realidad incontingente y ajena al cambio sustantivo. Una estrategia que descansa sobre la longeva pretensión de arrojar una descripción isomórfica capaz de vincular estructuralmente las palabras con la esencia del mundo. La ecuación de identidad que traza íntimamente el ser y la verdad, y que obedece a la mentada necesidad, ofrece respuesta al deseo de seguridad y estatismo del sujeto de la tradición, aferrado a las categorías de seguridad y de certeza.

Una correlación esta entre lenguaje y ser, entre lógica y ontología, que se conduce a lo largo de la pregunta por la verdad que inquiere el sujeto moderno. Este, al cierre de la centuria decimonónica, se halla hastiado del propio acontecimiento de la vida, a la que identifica con un sufrimiento perenne en tanto no ha sido capaz de imprimir sobre ella su voluntad. Hay una carencia de condiciones de posibilidad de la voluntad creadora que se suple mediante 
la configuración de una nueva voluntad, la voluntad de verdad, que resuelve el anhelo psicológico de certeza respecto de aquello que es tenido por verdadero. En consecuencia, la sintaxis de la voluntad se vio invertida en la medida en que el sujeto de la voluntad creadora, activo, cede ante el de la voluntad de verdad, de cariz paciente: al imbricar el lenguaje y el ser dentro de la lógica de la voluntad de verdad aquel es imbuido de una fuerza ontológica cuyas expectativas pasan menos por "crear" el mundo que por "desvelar" los misterios de su íntima esencia ${ }^{1}$. Las pretéritas pretensiones de la actitud metafísica de creación sólida del universo de los conceptos se desvanecen; la interpretación ocupa su espacio, mas también en caracteres hasta entonces no vistos. Nietzsche pretende una suerte de identidad entre creación e interpretación, de manera que esta suponga aquella: la creación del cosmos conceptual depende necesariamente de la condición interpretativa, que la sume en una atmósfera de incertidumbre que impide el pleno asentimiento, inmóvil y consumado, del sentido y de los significados. Y en este juego, el agente de la interpretación se "desvela", se determina junto con aquello a interpretar, todavía dado como misterio (Gasché, 1985: 21).

Ahora bien, es precisamente en el concepto de "creación" donde descansan la fuerza y la originalidad de la posición nietzscheana, estableciendo el suelo nutricio del lenguaje en la peculiaridad artística del sujeto en detrimento de la lógica, devolviendo a aquel su condición activa. Las leyes gramaticales se ven afectadas profundamente y con ellas las pretensiones del lenguaje, para el que se postula un original carácter ficticio y cuyo seno ha renunciado a las tautologías lógico-lingüísticas en beneficio de un dinamismo que exige trocar "continuamente ilusiones por verdades" (Nietzsche, 2007b: 21).

La remisión al origen ficticio del lenguaje, con sus respectivas implicaciones gramaticales, y el cambio paradigmático de la voz del sujeto, nuevamente activa, llevan a Nietzsche a concluir el rechazo de la existencia de un mundo verdadero y la afirmación de un horizonte perspectivista en el que destacan las aptitudes figurativas y metafóricas del propio sujeto. En suma, "por lo que se refiere al origen, sobresale la concepción del hombre como «sujeto crea-

\footnotetext{
${ }^{1}$ Cf. Nietzsche (2007b: 20): "se ha inventado una designación de las cosas uniformemente válida y obligatoria, y el poder legislativo del lenguaje proporciona también las primeras leyes de verdad".
} 
dor artístico», al que es esencial un «impulso a la formación de metáforas»" (Conill, 2007: 36).

El fondo metafórico del hombre pone de manifiesto la pluralidad de sentidos sobre la que se erige su estructura de existencia (Gasché, 1985: 11); una pluralidad identitaria articulada por la plurivocidad de un sujeto activo en cuya originalidad no existe la fijeza del mundo verdadero, sino el perspectivismo deviniente de una voluntad creadora. De este modo, se desvela que la verdad responde a una determinada "valorización", que a su vez obedece no a la verdad, sino a aquellas condiciones que garantizan la conservación y el crecimiento para la vida. No es necesaria la verdad; basta con la ilusión de que algo sea tenido por verdadero, pues "la vida tiene necesidad de ilusiones" (Nietzsche, 2010a, 19 [34]: 355), de afirmar su condición creadora por medio de la atribución de valores. De manera que la tradicional oposición entre el "mundo verdadero" y el "mundo aparente" se reduce a una cuestión de valor ${ }^{2}$, hermenéutica.

La construcción del mundo a lo largo de la historia de Occidente se tejió desde una red moral que silenció la polifonía en favor de un único grito de sentido; se impuso una máscara "simple, áspera, fea, repugnante" (Nietzsche, 2011a: 40) que redujo la condición humana, restringiendo su condición hermenéutica y valoradora en beneficio de categorías unívocas de validez.

La afirmación de la muerte de Dios pasa por ser la denuncia del enmascaramiento de la esencial ausencia de sentido del hombre y del mundo. Se trata de una radical experiencia de orfandad significativa que acaba por atravesar al sujeto decimonónico, quien se percibe frágil y caduco tras el derrumbamiento de las interpretaciones ulteriores que hasta entonces habían resguardado el sentido y la justificación del mundo como "verdadero":

Y por lo que hace a nuestro futuro, difícilmente se nos volverá a encontrar en la senda de aquellos jóvenes egipcios que por la noche vuelven inseguros los templos, abrazan las estatuas y quieren desvelar, descubrir, llevar a la luz clara absolutamente todo lo que con buenas razones se mantiene

\footnotetext{
${ }^{2}$ Cf. Nietzsche (2011a: 220): "Desde el instante en que la fe en Dios del ideal ascético es negada, hay también un nuevo problema: el del valor de la verdad. -La voluntad de verdad necesita una crítica [...], el valor de la verdad debe ser puesto en entredicho alguna vez".
} 
cubierto. No, ese mal gusto, esa voluntad de verdad, de "verdad a cualquier precio", ese delirio adolescente en el amor a la verdad -nos provoca rechazo: somos demasiado experimentados, demasiado serios, demasiado divertidos, demasiado profundos, estamos demasiado quemados para ello... Ya no creemos que la verdad siga siendo verdad si se le quita el velo; hemos vivido demasiado para creerlo. Hoy es para nosotros una cuestión de decencia no querer ver todo en su desnudez, no querer estar presente en todo, no querer comprender y "saber" todo (Nietzsche, 2014b: 721).

El fin del concepto de Dios como garante de las condiciones de la voluntad de verdad supone el fin de la vieja pretensión de verdad última. Sin embargo, a diferencia de sus contemporáneos, afligidos por la atmósfera nihilista epocal, Nietzsche encuentra motivos de feliz fecundidad ${ }^{3}$ al comprender que esto nos arroja a un plano de infinitas interpretaciones. Nietzsche percibe los trazos de una nueva forma de filosofía según la cual la realidad se reduce a un juego de interpretaciones superpuestas cuya dialéctica de valoración anula la posibilidad de un sustrato gnoseológico fundamental indubitable. Una aproximación hacia la verdad remotamente hermenéutica que le terminará por mostrar que la verdad es una máscara. Desde aquí Nietzsche extrae un conocimiento elemental para su filosofía: "todo es falso" (Nietzsche, 2008b, 2 [127]: 115).

\subsection{La verdad trágica y la vida}

La labor genealógica de Nietzsche es, al término, una profunda y sistemática crítica corrosiva de la verdad. Orientada por una conciencia emancipatoria la genealogía, al derrumbar los ídolos que sustentaban la voluntad de

${ }^{3}$ Cf. Nietzsche (2011b: 231-232): “«qqué significa toda voluntad de verdad?»... Y aquí toco yo de nuevo mi problema, nuestro problema, amigos míos desconocidos (-pues todavía no sé de ningún amigo): ¿qué sentido tendría nuestro ser todo, a no ser el de que en nosotros aquella voluntad de verdad cobre conciencia de sí misma como problema?... Este hecho de que la voluntad de verdad cobre consciencia de sí hace perecer de ahora en adelante -no cabe ninguna duda- la moral: ese gran espectáculo en cien actos, que permanece reservado a los dos próximos siglos de Europa, el más terrible, el más problemático, y acaso también el más esperanzador de todos los espectáculos”. 
verdad, concluye en un espacio de existencia trágico. Nietzsche hace radicar su posición respecto de la verdad "más allá del bien y del mal", esto es, en un punto ajeno a la moral que había prescrito la primacía de la verdad sobre la mentira; una creencia abnegada como "es la fe en un valor metafisico, en un valor en sí de la verdad" (Nietzsche, 2011b: 219) y que terminó por convertir el "mundo verdadero" en una "fábula" (Nietzsche, 2002: 57-58).

La caracterización nietzscheana del lenguaje por la cual este se emancipa de la lógica del ser y el espacio trágico al que ha caído la existencia tras el fin de la voluntad de verdad pone de manifiesto la genuina capacidad artística del hombre. Es mediante la construcción de metáforas que el hombre se apropia del mundo y le imprime sentido ${ }^{4}$. Dentro de este nuevo paradigma gramatical, trágico, se lleva a cabo la exigencia del "Ensayo de autocrítica" de El nacimiento de la tragedia, a saber, que todo sea subordinado a la óptica del artista. El hombre es artista en la medida en que por su capacidad metafórica confiere significado al mundo, un significado que no es ya epistémico, sino trágico. La pretensión de la voluntad de verdad, la búsqueda del isomorfismo entre las palabras y la esencia del mundo, se desvanece cuando se ejecuta la máxima del "Ensayo de autocrítica".

La dupla pensamiento-lenguaje y mundo continúa en la "gramática" de Nietzsche. No obstante, la cualidad de estos caracteres es ahora relativizada: si bien es cierto que el lenguaje configura la imagen del mundo, habrá tantos mundos, tantas concepciones de la existencia, como gramáticas, como formas de "valorización". La relativización de la ontología de la realidad que tiene lugar en la filosofía de Nietzsche está íntimamente ligada con el nihilismo europeo, pues ¿cómo podría mantenerse la pregunta por la verdad cuando se ha reconocido que existen tantas concepciones de la verdad como mundos -gramáticas- hay? La pluralidad de dimensiones de la realidad, esto es, el perspectivismo al que nos arroja el pensador alemán, introduce un devenir inaprensible para las reglas de la gramática tradicional, que se basaba en la fijeza y la regularidad de la rígida lógica: los conceptos ${ }^{5}$. A la luz de los rasgos

\footnotetext{
${ }^{4}$ Cf. Conill (1991: 210): "la proyección perspectivista del mundo tiene su origen en la imaginación poética".

${ }^{5}$ Cf. Nietzsche (2007b: 26-27): “el gran edificio de los conceptos ostenta la rígida regularidad de un columbarium romano e insufla en la lógica el rigor y la frialdad peculiares de la matemática".
} 
cientificistas de la condición moderna Nietzsche percibe un lazo irrompible entre la gramática moderna y su ciencia "la ciencia trabaja inconteniblemente en ese gran columbarium de los conceptos [...], se esfuerza en llenar en ese colosal andamiaje que desmesuradamente ha apilado y en ordenar dentro de él todo el mundo empírico, es decir, el mundo antropomórfico" (Nietzsche, 2007b: 33).

Continuando su estudio crítico del nihilismo, Nietzsche comprende que la crítica de la ontología cientificista moderna y de sus corolarios ha de conllevar irremediablemente el fin del maridaje esencial del lenguaje y el mundo que se hubo concretado en la verdad. Las verdades son ilusiones, por lo tanto, el lenguaje ya no es la vocalización del pensamiento claro y distinto. Conclusión a la que llega el autor, como ya se ha anticipado, gracias a su propedéutica genealógica. La crítica genealógica ha sacado a la luz que tras la verdad discurre subrepticiamente una psicología de devoción, la fe, como se ha apuntado líneas atrás, en un valor en sí de la verdad (Gasché, 1985: 15).

El Nietzsche genealogista ha denunciado los falsos ídolos que habían sido asociados al concepto de verdad. En su lugar, habiendo renunciado a las tentativas de aproximación teorética de la verdad la introduce en el espectro de la existencia; es más, la radica en el momento elemental de la vida, imbricando una en la otra y viceversa: la verdad tiene únicamente valor si sirve a la vida, y por ello, la verdad tiene un valor condicionado. La afirmación nietzscheana del nihilismo como rasgo de Europa ${ }^{6}$ hace presa en este momento: la desvalorización de los valores últimos, y entre ellos la verdad, hace imposible radicar la fundamentación del sentido en caracteres incondicionados, esto es, relativos a una hipotética voluntad de verdad. En el momento de Nietzsche es "el nihilismo un estado NORMAL. Nihilismo: falta la respuesta al «ipor qué?», ¿qué significa nihilismo? -que los valores supremos se desvalorizan" (Nietzsche, 2008b, 9[35]: 241).

${ }^{6}$ En una carta fechada a mediados de abril de 1886 Nietzsche escribe a Carl Fuchs insistiendo en que la palabra decadencia tenía ya entonces, bien entrada la segunda mitad de la centuria decimonónica, una función descriptiva; servía para definir la condición epocal de la vieja Europa (Nietzsche, 2011a: 162): "pero esto es décadence, una palabra que, como se comprende de suyo entre nosotros, no pretende rechazar sino solo designar". 
El valor de la verdad como categoría, como "en sí", se sostuvo a lo largo de milenios, desde Platón, como una devoción ciega. Sin embargo, dicha fe "ha muerto". El paradigma metafísico del "mundo verdadero" ha cedido su prioridad ante el horizonte trágico, el cual integra el dolor de la experiencia de la orfandad significativa del sujeto y la asume como aspecto estructural de la insalvable relación borrascosa del sujeto con el mundo. La verdad condicionada que se desprende de la filosofía nietzscheana es radicalmente dependiente de la vida: su valor responde ante las condiciones de superación de la vida efectiva. Una verdad condicionada es -valga la redundancia- condición de vida: vida y verdad se integran en el horizonte del sujeto trágico, para quien la pretensión de un mundo eidético ajeno a la indigencia y la decadencia del tiempo es una ilusión indeseable:

El punto de vista del "valor" es el punto de vista de las condiciones de conservación y de aumento con respecto a formaciones complejas de relativa duración de la vida en el seno del devenir:

- no hay unidades últimas duraderas, no hay átomos, no hay mónadas: también aquí "lo ente" ha sido introducido primero por nosotros (por razones prácticas, útiles según la perspectiva)

- "formaciones de dominio"; la esfera de lo dominante, constantemente creciendo o periódicamente disminuyendo, aumentando; o bien, bajo el favor y el desfavor de las circunstancias (de la nutrición -)

- "valor" es esencialmente el punto de vista para el aumento o la disminución de estos centros de dominio ("pluralidades" en cualquier caso, si bien la "unidad" no se encuentra en modo alguno en la naturaleza del devenir)

- un quantum de poder, un devenir, en la medida en que en ello nada tiene el carácter del "ser"

[...] no hay ninguna voluntad: hay puntuaciones de voluntad que constantemente aumentan o pierden su poder (Nietzsche, 2008b, 11 [73]: 388).

\subsection{El cuerpo como acontecimiento radical de la voluntad de poder}

El rechazo de la voluntad de verdad tiene como efecto inmediato el consecuente abandono del suelo en que esta hundía sus raíces, a saber, el "mundo 
verdadero". El hombre nietzscheano es indigente, no tiene un fondo último indubitable, claro y distinto, aunque no carece de suelo. Tal sustrato, no obstante, comienza y acaba en el propio sujeto; es condicionado: el cuerpo. Partiendo desde el cuerpo "la fuerza de los conocimientos no reside en su grado de verdad, sino [...] en su carácter de condiciones de la vida" (Nietzsche, 2014b: 795). El cuerpo juega un papel crucial en la obra de Nietzsche, pues sobre él articula, proyecta y despliega su novedosa concepción del hombre y del mundo: "es esencial partir del cuerpo y utilizarlo como hilo conductor" (Nietzsche, 2010b, 40 [15]: 848).

La peculiar condición del cuerpo hace imposible concretarlo como una mera unidad. En él se da una pluralidad irreductible que desvela la fuerza de las infinitas posibilidades de existencia del hombre. El cuerpo es tanto límite como infinitud: en su matriz yacen realidades varias donde unas fueron; otras pueden ser; otras jamás serán dentro del umbral que es el hombre. El cuerpo es el hilo conductor de la sabiduría de la vida (Martínez Becerra, 2008: 333). El ser humano es para Nietzsche una nueva concreción de unidad motivada desde la multiplicidad; una unidad fugaz y perecedera que se despliega sobre una jerarquización de valores sujeta a la constante confrontación contra otros tantos nuevos: es el cuerpo una unidad plural.

La ontología nietzscheana debilita la unidad de la realidad en una estrategia que rechaza las pretéritas pretensiones de la esencialización del ser; el fondo de la existencia aduce al cuerpo como integración tan sólida como voluble de infinitas personalidades: "el individuo contiene muchas más personas de las que él cree. «Persona» es solo una acentuación, un resumen de rasgos y cualidades" (Nietzsche, 2010b, 25 [363]: 516). Ahora bien, el cuerpo no es tampoco el fundamento ontológico, sino un estamento radical que atraviesa otras estancias de la realidad. La unidad del cuerpo como complejo juego de jerarquías antecede al individuo, que es síntesis coyuntural resultante de la pluralidad somática. Así puede sentenciar Nietzsche que el concepto de individuo es falso, "y el inventor de sí mismo será considerado durante mucho tiempo un extraviado" (Nietzsche, 2010b, 12 [12]: 281).

Nietzsche propone un hombre sostenido sobre el cuerpo. Un conocimiento profundo de la fisiología del cuerpo (Martínez Becerra, 2008: 334) lo descu- 
bre como una compleja red de interpretaciones de inaprensible sentido ${ }^{7}$ : el cuerpo interpreta; interpretaciones que cristalizan en posteriores valoraciones. De modo que en el hombre nietzscheano vida y cuerpo conforman una unidad sintética que transita sobre la interpretación de perspectivas; el sujeto nietzscheano es hermenéutico, pues la instancia metafísica del "ser en sí" ${ }^{\text {' }}$-el "mundo verdadero"- que sostenía la voluntad de verdad ha desaparecido:

La cuestión de los valores es más fundamental que la cuestión de la certeza: la última solo adquiere seriedad en el supuesto de que la cuestión del valor haya tenido respuesta.

Ser y apariencia, revisados psicológicamente, no dan por resultado ningún "ser en s'́, ningún criterio de "realidad", sino solo de grados de apariencia, medidos según la fuerza de la parte que le otorguemos a una apariencia (Nietzsche, 2008b, 7[49]: 220).

Más aún, Nietzsche sospecha que la relación tradicionalmente solidaria entre el hombre y el ser es incompatible con una vida vivida desde el cuerpo: "todo lo que entra en la conciencia como una «unidad» es ya enormemente complejo: nunca tenemos más que una apariencia de unidad" (Nietzsche, 2008b, 5 [56]: 161). Ser sujeto es ser interpretativo; el acontecimiento de la interpretación es un fenómeno ilimitado toda vez que se nutre no de un suelo provisto de fundamento, sino de un juego de fuerzas que en su interacción violenta se transforman y dan lugar a valoraciones. Este fondo hermenéutico es incompatible con los caracteres de la vetusta razón especulativa:

- no es esto lo que nos separa: que ni en la historia, ni en la naturaleza, ni detrás de la naturaleza reencontremos nosotros un Dios - sino que aquello que ha sido venerado como Dios nosotros lo sintamos no como "divino",

\footnotetext{
${ }^{7}$ Cf. Nietzsche (2008b, 5 [55]: 161): "Error capital de los psicológicos: consideran a la representación indistinta como una especie inferior de representación respecto de la clara: pero lo que se aleja de nuestra conciencia y por ello se vuelve oscuro, puede por ello ser en sí perfectamente claro. El volverse oscuro es cuestión de la perspectiva de la conciencia. La «oscuridad» es una consecuencia de la óptica de la conciencia, no necesariamente algo inherente a lo «oscuro»".

${ }^{8}$ Cf. Nietzsche (2008b, 7 [6]: 205): "el «hay necesidad de una sola cosa» y el «aspira al reino de Dios: y todo lo demás te será dado por añadidura» («lo demás» incluye también p. ej. el amor al prójimo, la moral en el sentido actual)".
} 
sino como caricatura santa, como moutonnerie, como absurda y lamentable niaiserie, como principio de la calumnia contra el mundo y contra el ser humano: en resumen, que nosotros negamos a Dios en cuanto a Dios. El colmo de la mendacidad psicológica del ser humano es agenciarse un ser como comienzo y como "En-sí" de aquello que, <según> su esquinado criterio de medida, se le aparece precisamente como bueno, sabio, poderoso, valioso- y eliminar entonces toda la causalidad gracias a la cual subsiste y tiene valor en absoluto cualquier bien, cualquier sabiduría, cualquier poder. En resumen, poner elementos de procedencia sumamente tardía y condicionada no como formados a lo largo de un proceso sino como "en sí" $\mathrm{y}$, en lo posible, como causa de todo el proceso de formación en absoluto (Nietzsche, 2008b, 11 [122]: 401).

La afirmación de la condición hermenéutica del sujeto nietzscheano no es gratuita ni reactiva, es decir, no parte de la simple negación de la voluntad de verdad (Martínez Becerra, 2008: 339). Nietzsche ha de presentar un elemento alternativo que procure garantías ontológicas a la realidad del sujeto. Dicho principio es la voluntad de poder, a través de la cual transita el cuerpo (Otero León, 2008: 24). En la vasta complejidad que es el cuerpo se suceden fuerzas que se enfrentan entre sí y de cuya colisión emerge el constructo llamado "vida", confeccionada en función de aquellos instintos que hayan sido establecidos jerárquicamente como dominantes: el hombre es el resultado de la conflictiva colaboración de muchas voluntades de poder que luchan por imponerse. La relación entre el cuerpo y la voluntad de poder se cifra en un círculo íntimo donde los instintos son aprehendidos por ella que, a su vez, nos hace retornar al cuerpo configurado. Un cuerpo en el que convergen la unidad sintiente del hombre con la pluralidad subyacente de las voluntades de poder y que compendia la concepción ontológica de Nietzsche: el modo de ser es la pluralidad, que, sin embargo, se concreta en una unidad tan real como coyuntural y precaria que ha renunciado a la pretensión de alcanzar un ser inmutable. El sujeto nietzscheano es cuerpo, esto es, voluntad de poder; y así, hermeneuta.

El Nietzsche genealogista ha rastreado las raíces de la verdad hasta identificarlas en la voluntad de poder, ontología de la conceptualización nietzscheana de la existencia y la realidad. Mediante la voluntad de poder se establece 
un choque elemental de estados y afectos que se superponen en el mismo hombre y la consecuente jerarquización de los mismos ${ }^{9}$, de donde emerge el sujeto corporal. Un sujeto inserto en la dimensión perspectivista emanada del constante juego de "valorización" que actualiza unas posibilidades de vida al tiempo que ignora y agota tantas otras más. El "exterior" del sujeto activo de la voluntad de poder que queda tras la jerarquización interna de fuerzas, conserva la apariencia de unidad sobre el vasto océano de pluralidad que como corporalidad lo conforma. Luego en virtud de la peculiaridad del ser del hombre es voluntad de poder. Más aún, especifica Nietzsche, dado el carácter aparente y múltiple de ella, el hombre es una pluralidad de voluntades de poder entretejidas en una unidad aparente que, sin embargo, es "real":

Si nuestro "yo" es para nosotros el único ser de acuerdo con el cual hacemos y comprendemos todo ser: ¡muy bien! entonces resulta muy justificada la duda de si no hay aquí una ilusión perspectivista -la unidad aparente en la que todo se une como en una línea del horizonte. Siguiendo el hilo conductor del cuerpo se muestra una enorme multiplicidad; está permitido metológicamente emplear el fenómeno más rico, que puede ser estudiado mejor, como hilo conductor para la comprensión del más pobre (Nietzsche, 2008b, 2 [91]: 103).

\section{§2. VolunTAD DE PODER Y HERMENÉUTICA}

La falsedad generalizada de los avatares del mundo agota la vieja lógica de la voluntad de verdad. En su lugar, Nietzsche pergeña una nueva estrategia sostenida sobre la condición plástica de la voluntad de poder. La voluntad de poder ocupa uno de los espacios fundamentales en la filosofía de Nietzsche, a saber, la cuestión de la realidad: "el problema de la vida: como voluntad de poder" (Nietzsche, 2008b, 9 [1]: 235). Si bien la voluntad de poder participa

\footnotetext{
${ }^{9} \mathrm{Al}$ respecto ha observado Deleuze que la voluntad de poder es "el elemento genealógico de la fuerza, diferencial y genético a la vez. La voluntad de poder es el elemento del que se desprenden a un tiempo la diferencia de cantidad de las fuerzas en relación, y la cualidad que, en esta relación, corresponde a cada fuerza" (Deleuze, 2013: 73-74).
} 
en la metafísica y la cosmología nietzscheana ${ }^{10}$, su posición principal está en el plano existencial: "y también vosotros mismos sois esta voluntad de poder -¡y nada más!” (Nietzsche, 2010b, 38 [12]: 831). La imbricación de la voluntad de poder en la vida es esencial, no resultando extraño identificarlas: ¿qué es prioritario en Nietzsche, la vida o la voluntad de poder? Nietzsche se muestra ambiguo; somos voluntad de poder y nada más, pero las implicaciones del "nada más" nublan más aún la respuesta. La voluntad de poder es naturaleza, es arte, es voluntad de verdad, es moral, es vida, etc. Con todo, la voluntad de poder es la bisagra por la que se armonizan el hombre y el mundo en una convergencia de unicidad -el hombre es voluntad de poder-y pluralidad -se pueden crear cualesquiera realidades en virtud de la "valorización"-. La voluntad de poder es la condición de posibilidad de la capacidad valoradora, la íntima condición plástica y artística desde la que se crean verdades, valores, como advierte Heidegger. El mundo, en suma, descansa al abrigo del pensamiento de la voluntad de poder. Luego desde la vida, el arte y la voluntad de poder se traza una línea que da al devenir unidad estructural ${ }^{11}$.

\subsection{El cuerpo hermenéutico como ser de la dimensión de lo inconsciente}

Lo consciente es la plasmación inmediata de la realidad humana, pero precisamente por ello no puede ignorarse que el sustrato sobre el que germina es un trasfondo de pluralidad de fuerzas enfrentadas que tratan de ganar un lugar privilegiado en la determinación jerárquica de las muchas perspectivas posibles. De tal modo que lo inconsciente, que es un aspecto nuclear de la existencia, conlleva que el conocimiento que podemos llegar a alcanzar de

\footnotetext{
${ }^{10}$ En la concepción cosmológica nietzscheana la actividad conjunta de la voluntad de poder y del eterno retorno constituyen y vertebran el núcleo del mundo (Nietzsche, 2010b, 38 [12]: 831): “-Este mundo es la voluntad de poder -iy nada más!".

${ }^{11}$ Cf. Heidegger (2013: 79): "esa determinación del arte como estimulante de la vida no quiere decir otra cosa que: el arte es una forma de la voluntad de poder. En efecto, "estimulante" es lo que impulsa, lo que intensifica, lo que eleva más allá de sí, el "más" de poder, o sea, simplemente, el poder, es decir, la voluntad de poder".
} 
nosotros mismos sea irremediablemente parcial. La unidad subjetiva deviene aparente. Mas ello no ha de tomarse como un deplorable estado terminal de un sujeto vencido por las fuerzas que lo dominan, sino como el triunfo de la vida que ha sobrevivido al desprecio: una vez ha desaparecido la creencia en el ser en sí-incólumemente unitario e incorruptible- la apariencia pasa de ser un estamento peyorativo a una dulce perspectiva vital, dado que lo aparente no es de suyo irreal, ni fábula ni imitación. Nietzsche alcanza a contemplar que la consciencia emerge del cuerpo y es estrictamente correlativa a él. Y en la medida en que se es sobre una pluralidad inabarcable e inaccesible de perspectivas, el sueño dogmático que aspiraba a la autoconciencia resulta no solo imposible, sino también indeseable (Otero León, 2008: 25): tamaña multiplicidad aplacaría la conciencia del sujeto mediante su insostenible peso. Por ello, cabe imaginar que ante la dimensión de lo inconsciente el cuerpo, el ser, sea hermenéutico.

El cuerpo es contenedor de una multitud de fuerzas -impulsos, deseosinstintivas en su mayoría inconscientes que han impulsado la vida (Gadamer, 2008: 13-44). La aproximación a tales dominios resulta pavorosa, pues supone el enfrentamiento de una dimensión cuyo sentido ulterior está vedado. Las herramientas cognitivas de las que tanto se enorgulleció la civilización moderna son insuficientes, ya que tan solo abarcan la superficie de la existencia, esto es, la manifestación a través del cuerpo de aquellas fuerzas que han prevalecido sobre las demás. Por ello afirma Nietzsche que tomada la corporalidad como ser del hombre esta abisma al propio sujeto al hacerle notar cuán fútil es la conciencia sobre la que creyó construir la "vida" y la "realidad". El conocimiento de sí mismo desde los estrictos caracteres del oráculo de Delfos termina por resultar imposible. Las fuerzas impuestas a lo largo de la tradición han afectado el imaginario colectivo y por ende el individual, impidiendo identificar cuáles de los rasgos específicos del sujeto concreto son como tal genuinos y cuántos, en cambio, heredados. Nietzsche concluye que la comprensión de esta condición lleva al hombre a sentirse "extraño de sí mismo", a cuestionarse quién y qué es ser yo: "nosotros los que conocemos somos desconocidos para nosotros, nosotros mismos somos desconocidos para nosotros mismos [...]... Necesariamente permanecemos extraños a nosotros mismos" (Nietzsche, 2011b: 25-26). 
Es preciso hacer en este momento una matización a propósito de la ontología de Nietzsche. Que la voluntad de poder sea un elemento estructural que armoniza y canaliza la relación de fuerzas no la convierte en un fundamento ulterior del ser del hombre. Acorde con su caracterización hermenéutica del hombre, la voluntad de poder conserva también los rasgos de apariencia -y, por ende, de precariedad y contingencia- y pluralidad que determinan el imaginario antropológico de Nietzsche: la voluntad de poder es real en tanto que es perspectiva de la realidad; una realidad de cuyo fondo insondable emerge tras el juego conflictivo un dominio coyuntural de fuerzas imperantes motivadas y traducidas por el constante flujo de la voluntad de poder, que torna imposible la posibilidad de una realidad en sí, inmutable e incólume (Fink, 1984: 95).

El hombre nietzscheano es el resultado sintético de un cúmulo de instintos y pasiones que albergan posibilidades virtualmente infinitas y entre ellas incompatibles. La realidad sintética refleja la contradicción en la que vive y se afirma el sujeto hermenéutico: reconoce la estructura opositora sobre la que es y se integra dentro de ella como mecanismo de resolución. Vivir en la contradicción es la estrategia de existencia propuesta por Nietzsche, dado que implica vivir contemplando el pozo de pluralidad al que estamos abiertos y que nos sostiene en la unidad aparente que se nutre de la posibilidad constante del cambio. Este hombre surgido al abrigo de la síntesis pulsional e instintiva ha renunciado a la pretensión de la unidad estructural de lo humano; al mismo tiempo no admite que la pluralidad signifique una integración caótica de distintos avatares existenciales emanados del libre arbitrio de los instintos.

La filosofía hermenéutica nietzscheana es una oda a la salud (Santiago Guervós, 2004: 498 y ss). Asentada sobre el cuerpo, busca canalizar los instintos más poderosos como incombustible motor de una vida de generación y crecimiento. Para ello el cuerpo es pensado en términos no estrictamente biologicistas, sino hermenéuticos: el cuerpo es un texto que interpretar. La lectura literalista únicamente arroja concreciones fisiológicas brutas, o sea, la reducción simplista del organismo a hormonas y procesos bioquímicos varios; los caracteres del libro han de ser interpretados, ya que del estrato fisiológico emanan los juicios morales y las valoraciones que definen la vida como cuerpo. 
La interpretación multiplica el libro de la vida humana. El texto fundamental deviene tantos otros de acuerdo con la perspectiva: la interpretación se hace texto que habrá a su vez de ser interpretado. Esta dinámica ilimitada de interpretaciones ilustra que el hombre sintético al que se refiere Nietzsche es la interpretación última ${ }^{12}$ de todas las fuerzas que conforman al sujeto. Esta interpretación última, que es el cuerpo actual, es necesariamente transitoria, pues sigue inserta en el horizonte del conflicto interpretativo: tras la unidad aparente del sujeto palpita un fondo salvaje de lucha. No es posible especificar el sentido de la concreción de las determinaciones hermenéuticas, ya que el conflicto interpretativo es solo parcialmente cognoscible:

En el momento, sin embargo, en que por fin actuemos, nos veremos determinados por un género de motivos distinto del que aquí se tenía en consideración, el de la "imagen de las consecuencias". [...]; obra algo corporal que aparece de manera por completo inesperada, obra el humor, obra, irrumpiendo, un afecto cualquiera que estaba a punto de saltar: en una palabra, obran motivos que en parte no conocemos en absoluto, en parte conocemos muy mal, y que de ningún modo hemos podido tener en cuenta y comparar de antemano. Es probable que también entre ellos tenga lugar una pugna, un tira y afloja, que se compensen o se hundan las partes [en litigio] -y esa sería la verdadera "pugna de los motivos":- algo que para nosotros resulta totalmente invisible e inconsciente. He evaluado las consecuencias y el buen éxito, introduciendo así un motivo muy importante en el frente de batalla de los motivos, -mas ese frente de batalla ni lo establezco yo ni tampoco lo veo: la pugna misma es algo que se me oculta, y lo mismo hay que decir de la victoria en cuanto tal victoria; de lo que sí me entero es de lo que a la postre hago,-- pero de cuál sea el motivo verdadero que con ello resulta vencedor, de eso no me entero. Estamos, sin embargo, acostumbrados a no incluir en la evaluación todos esos procesos inconscientes y a pensar antes de hacer algo solo en aquello de lo que somos conscientes: y así confundimos la pugna de los motivos con el comparar las consecuencias de diversas acciones posibles, - ¡ iconfusión esta de las más graves, de las de más funestas consecuencias para el desarrollo de la moral! (Nietzsche, 2014a: 559). finitiva.

12 "Última", en términos cronológicos, o sea, la más reciente; nunca puede ser "última" como de- 
La voluntad de poder atraviesa el cuerpo. En virtud de ella las pulsiones e instintos se enfrentan por el dominio sobre el sujeto a lo largo de un juego, no obstante, eminentemente humano. A Nietzsche "le gusta -dice Deleuzeoponer la voluntad de poder al querer-vivir schopenhaueriano, aunque solo sea en función de la extrema generalidad de este. Si, al contrario, la voluntad de poder es un buen principio, si reconcilia al empirismo con los principios, si constituye un empirismo superior, es porque es un principio esencialmente plástico que no es más amplio que lo que condiciona, que se metamorfosea con lo condicionado, que se determina en cada caso con lo que determina" (Deleuze, 2013: 74).

\subsection{La creación artística del cuerpo por la voluntad de poder}

Cuando Nietzsche reclama el cuerpo como ser del hombre está rechazando con ello las tentativas metafísicas que aportaron un origen divino. El ser humano queda irremediablemente inserto en la naturaleza, que es su naturaleza: no hay una naturaleza humana divinizada, sino los trazos específicos que el desarrollo biológico le ha concedido. Y ahí reside, sin embargo, en los rasgos típicamente humanos, su maravillosa cualidad: la condición ficticia y fabuladora, la cual es el mecanismo evolutivo de la especie, obliga a reinventar el mundo de la vida, que no se limita a la mera supervivencia fisiológica. Nietzsche lo sentencia al señalar que solo el hombre tiene fines y metas, fines y metas que en su realización se identifican con sus propios medios para concretarse en la salud de las nuevas auroras, que devienen virtud última:

Salud del alma. - La popular fórmula moral médica (cuyo autor es Aristón de Quíos): "la virtud es la salud del alma" - debería por lo menos, para ser utilizable, transformarse en: "tu virtud es la salud de tu alma". Porque no hay una salud en sí, y todos los intentos de definir algo así han fracasado estrepitosamente. De tu finalidad, de tu horizonte, de tus fuerzas, de tu impulso, de tus errores y especialmente de los ideales y fantasmas de tu alma depende la determinación de qué habrá de significar salud, incluso para tu cuerpo. Hay por lo tanto innumerables saludes del cuerpo; y cuanto más se permita levantar de nuevo la cabeza a lo singular e incomparable, cuanto 
más se olvide el dogma de la "igualdad de los hombres", tanto más tendrá que desaparecer para nuestros médicos el concepto de una salud normal, junto con el de una dieta normal o el del proceso normal de una enfermedad (Nietzsche, 2014b: 800).

La vindicación del hombre como ser natural -como cuerpo- es una denuncia más rica que la mera reducción de este a las funciones tróficas: es la consideración del sustrato inconsciente que nos abre a la pluralidad de sentidos y que exige la constante tarea de la asignación de valores y la finura del gusto refinado capaz de discriminar entre "bueno" y "malo". El hombre como ser natural se revela como un enigma irresoluble que, sin embargo, nos instiga a ofrecer tentativas resolutivas estructuralmente precarias y sujetas a la valoración perenne que juzga y jerarquiza.

La condición del hombre como ser natural es hermenéutico, pues su rasgo distintivo es la valoración. Ser hombre, dice Nietzsche, consiste, en último término, en crear una cultura, esto es, un horizonte de valores desde los que comprender, juzgar, censurar, afirmar o rechazar los fenómenos del mundo. Un marco cognitivo, lo que Foucault bautizó como "episteme"13, que emana de la determinación de la voluntad de poder, juez último que sentencia la gradación valorativa de los instintos. La voluntad de poder es, por tanto, el dominio de una fuerza rebosante capaz de integrar a todas las demás bajo una misma cúpula. Sin embargo, no se hace justicia con la filosofía de Nietzsche si se convierte la voluntad de poder en un desatado torrente de dominación cruel y despótica. Estos cauces, también transitables por la voluntad de poder, pertenecen a los espíritus más pueriles que contemplan la dominación como

${ }^{13} \mathrm{Cf}$. Foucault (2006: 7): “[...] un estudio que se esfuerza por reencontrar aquello que a partir de lo cual han sido posibles conocimientos y teorías; según cuál espacio de orden se ha constituido el saber; sobre el fondo de qué a priori histórico y en qué elemento de positividad han podido aparecer las ideas, constituirse las ciencias, reflexionarse las experiencias en las filosofías, formarse las racionalidades para anularse y desvanecerse quizá pronto. No se tratará de conocimientos descritos en su progreso hacia una objetividad en la que, al fin, puede reconocerse nuestra ciencia actual; lo que se intentará sacar a luz es el campo epistemológico, la episteme en la que los conocimientos, considerados fuera de cualquier criterio que se refiera a su valor racional o a sus formas objetivas, hunden su positividad y manifiestan así una historia que no es la de su perfección creciente, sino la de sus condiciones de posibilidad". 
la imposición de uno sobre otro; la voluntad de poder no es fuerza embrutecida, sino el refinado instinto que triunfa sobre la fuerza misma: "ser señor".

Lo inconsciente no es terreno donde moren lo espontáneo y el libertinaje; al contrario, comprende Nietzsche, requiere de la responsable mesura de quien situándose frente al abismo de la infinita pluralidad se exige "ser señor". Nietzsche entiende que no puede hablarse de la libertad de la acción cuando el agente se entrega de manera irrestricta a los impulsos y pasiones. El azar y el oscuro fondo de pluralidad que caracterizan la concreción del hombre en el mundo no pueden ser, sin embargo, sino condiciones de posibilidad del cuerpo, nunca los principios regentes de la conducta; no son fines, sino medios en el proceso de creación de la propia vida: el hombre no es un ser inmutable y perfectamente trazado y dispuesto desde el origen, sino un campo que cultivar para, como apunta en el subtítulo de Ecce homo, "llegar a ser lo que se es", un proceso a lo largo del cual, se siente en casa:

Siempre en casa. - Un día alcanzamos nuestra meta - y entonces señalamos con orgullo los largos viajes que hemos hecho para llegar a ella. En verdad, no nos dábamos cuenta de que viajábamos. Pero llegamos tan lejos porque en cada sitio nos imaginábamos estar en casa (Nietzsche, 2014b: 825).

El hombre como su más bella obra artística no puede sostenerse desde los inquebrantables estamentos de la imperturbable lógica; la pluralidad de caras a la que estamos abiertos exige la tarea hermenéutica de constituirnos sobre una neblina que oscurece nuestro ser y que lo torna inaccesible. La demanda socrática de razón a cualquier precio es una petición asfixiante e inhumana, pues obliga precisamente a prescindir de nuestros rasgos más humanos. Nietzsche nos procura una nueva estrategia de virtud al vindicar el juego oscuro y secreto de la voluntad de poder: "Concepto de «perfección»: no solo mayor complicidad, sino mayor poder (-necesita ser no solo una mayor masa-)" (Nietzsche, 2008b, 2 [76]: 98).

Cuando Nietzsche afirma el carácter estético de la moral no hace sino sostener su condición afirmativa y creativa, por un lado; y, por otro, reconocer, otra vez, el fuerte y doloroso compromiso ascético del hombre como cuerpo que apunta a las más altas cumbres. Por lo tanto, el maridaje de la ética y la 
estética arroja el compromiso del sujeto a consumar esforzadamente su acción creadora en un mundo que reconoce fuente de dolor y sufrimiento.

Igualmente la propuesta de una moral reducida a estética se muestra como la respuesta coherente de una filosofía que ha abdicado, tras la muerte de Dios, del ser sustancial del mundo, ya que la apelación a lo absoluto se ha desvanecido. La alternativa pasa a promover la creación de esta misma desde la radical orfandad de la pérdida de la verdad objetiva. La verdad deviene apariencia y queda inscrita en el juego autofundante de los valores, de cuya determinación emanará la significación de los distintos modos de vida. Esto, y no el banal goce hedonista, significa la transmutación de la ética a la estética: una nueva moral fortalecida estéticamente gracias a su origen creativo, siempre nueva y reinventada, que hace desaparecer a aquella moral solidificada e impuesta. Y así, Nietzsche conmina a "dar a la existencia una significación estética" (Nietzsche, 2008a, 11 [162]: 794). La moral tradicional, concluye finalmente el Nietzsche genealogista, es "inmoral", dado que su raíz es otra.

La raíz de la moral es inmoral si pensamos dicha acepción a partir de los modos tradicionales de verdad y ser; es moral en un sentido eminentemente estético, esto es, como expresión de jerarquías de valor. El hombre es un ser moral, dice Nietzsche, en tanto que no es posible vivir sin valorar; vivir es valorar, y por tanto, la raíz de la vida es estético-artística. El hombre es un ser fabulador, creador de sus propias condiciones de existencia:

Que el valor del mundo reside en nuestra interpretación (-que quizá en alguna parte sean posibles otras interpretaciones, diferentes de las meramente humanas-), que las interpretaciones habidas hasta ahora son estimaciones perspectivistas en virtud de las cuales nos mantenemos en vida, es decir, en la voluntad de poder, de crecimiento del poder, que toda elevación del hombre lleva consigo la superación de interpretaciones más estrechas, que toda fortificación y ampliación de poder que se alcance abre nuevas perspectivas y hace creer en nuevos horizontes -esto recorre mis escritos. El mundo que en algo nos concierne es falso, es decir, no es un hecho, sino una invención y un redondeo a partir de una magra suma de observaciones; está siempre "fluyendo", como algo que deviene, como una falsedad que continuamente vuelve a trasladarse, que no se acerca nunca a la verdad: porque - no hay "verdad" (Nietzsche, 2008b, 2 [108]: 108). 
De este modo el fondo de la moral revela su condición poiética, artística, que no descansa sobre un suelo de objetividad, sino sobre la propia actividad del sujeto que juzga y valora, o sea, que vive. El recurso a un sustrato objetivo colisiona frontalmente con las estimaciones de valor; observación esta todavía imperceptible para el hombre moderno, en quien se aprecia una "falta de educación estética" (Nietzsche, 2010a, 19 [313]: 411).

\subsection{La voluntad de poder como principio plástico y artístico de vida}

La voluntad de poder atraviesa el fondo deviniente del mundo, lo cual hace imposible la contemplación de la voluntad de poder cual si fuese la voluntad schopenhaueriana, esto es, una clase de sustancia inmanente y sustantiva. Es plural, y de ella emana todo arte, es decir, las condiciones de acción y acrecentamiento de la vida particular, de modo que esta germina de aquella, a la par que la vida traza los rasgos de la voluntad de poder; que la religión, la moral, el conocimiento o la sociedad sean fenómenos artísticos significa que son frutos de la fuerza creadora de la voluntad de poder. Se trata entonces de imprimir fuerza vigorosa en la voluntad de poder, que su fuerza creadora afirme la existencia como cuerpo. La voluntad de poder, como pulsión de vida, es un instinto netamente activo:

La vida misma es para mí instinto de crecimiento, de duración, de acumulación de fuerzas, de poder: donde falta la voluntad de poder hay decadencia. Lo que yo asevero es que a todos los valores supremos de la humanidad les falta esa voluntad, -que son valores de decadencia, valores nihilistas los que, con los nombres más santos, ejercen el dominio (Nietzsche, 2007a: 35).

El horizonte de precomprensión nietzscheano reescribe las condiciones de las actividades valoradora y jerarquizadora: la voluntad de poder abraza la pluralidad perspectivista trágica de la realidad, su dicha y su amargura, y acrecienta las condiciones de posibilidad del sujeto concreto. Como se ha dicho, no cabe pensar una imagen única y unitaria de la voluntad de poder; la voluntad de poder es condición de vida, pero ella misma, en cuanto raíz del 
fondo de vida trágico de la verdad hermenéutica, carece de esencia. Así, la polifonía y la plasticidad de la voluntad de poder "hablan" simultáneamente: confiesa Zaratustra haber hallado voluntad de poder allí donde vio seres naturales $^{14}$; ahora bien, en cada ser natural, por su condición plural, se superponen ilimitadas voluntades de poder cuya determinación definitiva viene de la jerarquización que la propia voluntad de poder impone sobre sí misma. De este modo la voluntad de poder se presenta como un elogio trágico de la vida y de creación plástica de la verdad: la fuente de vida y la fuente de valoración se armonizan en el concepto de voluntad de poder, "porque la vida es cabalmente voluntad de poder" (Nietzsche, 2005: 235).

Esta integración, sin embargo, no supone una superposición de la vida en la valoración o viceversa. No es una amalgama de identidades donde una y otra tratan de conservar sus respectivos significados en una nueva unidad amenazada por tensiones estructurales. Es, por el contrario, una unidad sintética donde vida y voluntad de poder no pierden sus significados, sino que se comprenden como la misma entidad: la voluntad de poder es la capacidad de crear valores y de jerarquizarlos para que estos se concreten en una manifestación de vida concreta: la realidad es la encarnación de la voluntad de poder. Así, el sujeto nietzscheano es uno trágico, pues en él se sintetizan lo fácil y lo difícil, lo bello y lo horroroso (Santiago Guervós, 2004: 475).

Esta afirmación resulta definitiva y, no obstante, no debe inducir a fáciles errores interpretativos. La vida es voluntad de poder, mas como se ha insistido, esta no se agota en una inexpresiva lectura biologicista que habría de llevar a Nietzsche a ser considerado un cientificista más. La voluntad de poder es ante todo la capacidad de valorar, de imprimir sentidos en el mundo y de crear verdades con ellos; en estos términos, es vida y realidad. La sentencia de que la vida es voluntad de poder, por tanto, obliga a distinguir el clásico locus griego de la vida como obra de arte en el pensamiento nietzscheano. Toda vida tiene en la voluntad de poder su sustrato, pero no toda vida es digna de ser amada. Esta imagen de dignidad de la vida es una remisión de la Apología de Sócrates, donde el ateniense sostiene que una vida sin filosofía no es digna

\footnotetext{
${ }^{14}$ Cf. Nietzsche (2009: 176): “en todos los lugares donde encontré seres vivos, encontré voluntad de poder".
} 
de ser vivida ${ }^{15}$, entendiendo por tal aquella consistente en conversar a diario acerca de la virtud.

\subsection{La voluntad de poder como fuerza hermenéutica}

El elemento fundamental de la voluntad de poder, la creación de valores $\mathrm{y}$ verdades que conforman el mundo humano, tiene su origen en la vida. El devenir esencial de esta hace de la voluntad de poder plástica fuerza interpretadora de las distintas realidades posibles que se suceden. Allí donde hay una vida que vive emergen las verdades; mientras la verdad, en singular, es síntoma de una vida decadente que tan solo pretende conservarse en la ilusión eidética de la incólume presencia del ser que mora en el "mundo verdadero".

La proposición ontológica nietzscheana percibe la verdad en la pluralidad, la cual se agolpa en una amalgama todavía indeterminada de realidades y verdades superpuestas siempre abiertas en un horizonte perspectivista cuyo sentido y significado se colma y concreta mediante una interpretación, mediante una adjudicación de valor jerarquizada sobre tantas otras ${ }^{16}$, siempre falible en tanto que remite al fondo trágico en devenir de la verdad hermenéutica que es la voluntad de poder.

A la luz del núcleo hermenéutico de la voluntad de poder, la verdad y el error dejan de ser categorías indubitables, relativas a la epistemología de la metafísica del "mundo verdadero", y se introducen irremediablemente en la experiencia de existencia del sujeto sintético de la trágica voluntad de poder. Que la vida sea voluntad de poder es lo que introduce en el mundo la verdad y el error perspectivista, pues lo sumerge en el fecundo frenesí del devenir y la pluralidad de esencial asignificación. Un suelo nutricio que empuja la con-

${ }^{15}$ Cf. Platón (1981, 38 a : 180): "si, por otra parte, digo que el mayor bien para un hombre es precisamente este, tener conversaciones cada día acerca de la virtud y de los otros temas de los que vosotros me habéis oído dialogar cuando me examinaba a mí mismo y a otros, y si digo que una vida sin examen no tiene objeto vivirla para el hombre, me creeréis aún menos. Sin embargo, la verdad es así, como yo digo, atenienses, pero no es fácil convenceros".

${ }^{16}$ Cf. Nietzsche (2010b, 4 [207]: 127): “en el hombre anidan tantos espíritus como animales en el mar -y luchan unos contra otros por el espíritu "yo"; lo aman, quieren que salte sobre sus espaldas, se odian mutuamente a causa de este amor". 
sideración del valor de la vida hacia un horizonte cuyo sustrato, sobre el cual se yergue la experiencia del ser en devenir, es una matriz articulada desde una interpretación consciente de su propio fondo falaz: la realidad y la vida humana están sumidas en una incertidumbre esencial cuyo sentido y verdad se determinan constantemente en el libre y perentorio ejercicio deviniente de la voluntad de poder (Romero de Solís, 1981: 15).

En la creación de verdades por la voluntad de poder intervienen fuerzas interpretativas que convierten al sujeto de poder en una sintética pluralidad identitaria de perspectivas y posiciones desde las que se da contenido a la acción que, en virtud de su poder, aspira a acrecentarse: la acción se acrecienta cuando el sujeto es capaz de darse sus propias metas y fines. Las diferentes perspectivas que articulan el núcleo específico de la acción creadora de la voluntad de poder no son, sin embargo, simples prismas y posiciones. En ellas se despliega en toda su "virulencia" la voluntad de poder: las distintas ópticas guardan una relación recíprocamente tensa a lo largo de un conflicto en el que se oponen entre sí, agotándose, consumiéndose y fortaleciéndose en el juego esencial del ser en devenir.

En la pulsión de vida de la voluntad de poder se agolpa una ilimitada cantidad de fuerzas e instintos que luchan entre sí por afirmarse. La victoria de una(s) sobre el resto la determina la fuerza creadora. Ahora bien, entiende Nietzsche que la creación de la obra de arte que es el hombre necesita de caracteres cualitativamente mayores que los del simple pluralismo cuantitativo. De contar únicamente con este criterio numérico, seríamos arrojados en un inabarcable océano de posiciones y verdades que imposibilitaría la elección cuasiconsciente y jerárquica de los valores superiores. Nietzsche exige, además, la tragedia del perspectivismo, el cual imprime sobre la inmensidad inerte de la pluralidad numérica el dinamismo y el devenir dionisiaco de la interpretación hermenéutica que devuelve a la vida su inocencia, la inocencia de un niño: "en la medida en que la palabra «conocimiento» tiene sentido, el mundo es cognoscible: pero es interpretable de otro modo, no tiene un sentido detrás de sí, sino innumerables sentidos, «perspectivismo»" (Nietzsche, 2008b, 7 [60]: 222).

El perspectivismo nietzscheano es sumamente complejo. Parte de la experiencia de la muerte de Dios, que anega las expectativas de una perspectiva 
última que unifique todas las demás. La pérdida de la verdad absoluta procurada por la metafísica del mundo suprasensible ha traído consigo una precariedad esencial que en su contingencia halla, sin embargo, necesidad: el fundamento de la realidad se constituye mediante apariencias que se aprecian perspectivísticamente. Y esta es una condición necesaria que se ha postulado en su corpus como verdad: la verdad es el carácter perspectivista de la vida y sus cualidades hermenéuticas, la apropiación de los rasgos de la existencia como cuerpo mediante la creación y la jerarquización de valores. La verdad integra las condiciones de vida, siendo la "mentira" y el "error" los caracteres que delimitan las perspectivas. La apariencia juega por tanto un doble rol: es de tal naturaleza porque está restringida a la perspectiva que impone la vida humana, al mismo tiempo que verdadera y necesaria en tanto que condición de posibilidad de los constituyentes de la existencia del hombre encarnado. La apariencia se extiende a lo largo de todo lo real, mientras que la perspectiva es la máxima disposición humana que da forma y confecciona como "verdad" una falsa unidad en el devenir. En virtud del carácter fabuloso de toda verdad y valor, el perspectivismo toma conciencia de su propia dimensión perspectivista: con la muerte de Dios y, con Él, el sentido y la verdad únicos, la voluntad de poder se adueña del derecho de verdad. Que la voluntad de poder afirmadora se adueñe del derecho de la verdad significa, en realidad, que la vida ha tomado de nuevo, como dijera Wilde, su "derecho de primogenitura"17; que la existencia sea un derecho del hombre en cuanto que existe es la significación de la transvaloración. La propia existencia, la propia vida ha sido redimida, por lo que no necesita ya de instancias externas y superiores, pues ella misma es razón de sí: la voluntad de poder como derecho de la verdad hace que la vida se procure sus propias metas y fines, que experimenta íntimamente, y que se despliegue en plenitud en su curso reapropiándose de sí en cada acontecimiento de creación afirmadora.

La pérdida de la unidad estructural del mundo es también la del sentido ulterior; la muerte de Dios anula las viejas tentativas escatológicas de un destino racionalmente trazado. El desgarramiento de la metaconciencia del

${ }^{17}$ Cf. Wilde (2016: 127): "somos una especie degradada y hemos vendido nuestro derecho de primogenitura por un plato de hechos". 
mundo inteligible ha cegado al futuro de toda meta: "inocencia del devenir". Una nueva disposición cosmológica y existencial donde la apariencia se ha convertido en el ámbito de la verdad nacida de la solidaria integración de la pluralidad y el perspectivismo que responden, a su vez, al fondo trágico del ser en devenir. Y como no existe realidad fuera de las interpretaciones, que remiten a su vez a la voluntad de poder, la realidad ha quedado radicada más allá del bien y del mal, ha sido despojada de toda culpa, es inocente, es voluntad de poder. Dado que la voluntad es la fuente de valoración y de interpretación, todo esfuerzo hermenéutico parte de ella. Entonces, por un lado los valores y las interpretaciones se encuentran dentro de los márgenes de la voluntad de poder; al mismo tiempo, la verdad de la realidad es hermenéutica, es decir, se articula a través de los valores y de las interpretaciones que emanan de la voluntad de poder. Así pues, con todo, la "inocencia del devenir" como cosmovisión según la cual no existe realidad fuera de las interpretaciones es la afirmación de la verdad de la vida como la propia experiencia de vida, radicada en sí misma y ceñida en su condición de fuente de valoración. La "inocencia del devenir" es la cosmovisión redimida de los ideales del "mundo verdadero". En ella la vida se comprende como voluntad de poder.

El perspectivismo de la filosofía de Nietzsche juega un doble efecto, condicionando tanto la perspectiva del hombre dentro de un mundo potencialmente infinito como destacando la esencial limitación de una filosofía que ya no puede postularse absoluta. La filosofía de Nietzsche es una filosofía de cierta menesterosidad. Una pobreza, una limitación que, sin embargo, ha de ser explicada. No es una contradicción la afirmación de que en su obra se citan tanto la sobreabundancia como la pobreza, pues son términos que remiten a contenidos heterodoxos que no entrañan la antonimia ordinaria de nuestro lenguaje. La sobreabundancia y riqueza nietzscheana, como la menesterosidad, nada tienen que ver con el oropel ni con la acumulación de alhajas. Lo primero alude a la fuerza de las interpretaciones. Mientras que la menesterosidad tiene inmediata relación con la lógica de decadencia y de finitud que sostiene la vida dionisiaca. Nada puede escapar del ciclo de generación y corrupción de una vida trágica, tampoco el pensamiento. De ahí que este sea "limitado", o sea, necesariamente sujeto a la indigencia de la caducidad de todo lo contingente. Que la filosofía nietzscheana sea limitada significa 
pobreza en estos caracteres de inminente decadencia y degeneración; rasgos estos que la alejan del curso de una filosofía sistemática con pretensiones últimas que encierre todas las posibilidades de existencia y cuyo "fin" sea la actualización de todos ellos. Es decir, es limitada porque nunca podrá ser entelequia de sí misma, pues esto significaría reintroducirla en los términos "gramaticales" del ser eterno e incontingente de la tradicional escatología metafísica occidental.

\subsection{La voluntad de poder como poiesis: ruptura y futuro}

La muerte de Dios ha puesto fin a la longeva tradición del ser, la de la verdad absoluta y de la unidad esencial de toda referencia valoradora. Sin embargo, en esta disrupción hay una especie de transvaloración de las formas filosóficas durante la cual la verdad se fragmenta en indeterminadas perspectivas plurales que remiten a las condiciones radicales de la vida encarnada: la verdad se convierte en voluntad de poder ${ }^{18}$. La verdad, la voluntad de poder y la vida son los tres vértices del triángulo de la existencia, que a su vez tiene su límite en las propias condiciones de vida dadas, pues este triángulo de existencia es existencia como cuerpo. La creación artística de la vida estética no se emprende desde la nada ni es tampoco el resultado de un paroxismo idealista típico del egoísmo especulativo; en el trasfondo de la vida las muchas voluntades de poder se enfrentan y limitan entre sí, determinando en tal pugna el horizonte de potencia de la vida. Si la voluntad de poder era una fuerza hermenéutica, continuando la metáfora gadameriana, su horizonte de conformidad y despliegue es la alteridad del sujeto con sus propias perspectivas posibles.

La verdad, en tanto resultado artístico, es una "mentira", una "ficción" de cuya condición ficticia se tiene conocimiento, es decir, el hombre se sabe creador de valores y verdades. Vivir es tragedia, luego excede los márgenes del conocimiento epistémico; vivir significa poetizar, integrar al sujeto sintético creador de verdades en sus propias ficciones para impregnarlas de

${ }^{18}$ Cf. Nietzsche (2008b, 9 [36]: 242): "la voluntad de verdad como voluntad de poder". 
sentido, crear sus metas y fines, desde su radical experiencia de existencia encarnada: “-¿Qué son pues nuestras vivencias? ¡Mucho más lo que introducimos en ellas que lo que en ellas hay! ¿No habrá que decir incluso que en ellas no hay nada? ¿Qué vivir (algo) es fabular?-" (Nietzsche, 2014a: 556). Precisamente por su remisión fundamental a la vida la voluntad de poder se concreta en una perspectiva de superación y crecimiento: crea valores que condicionan favorablemente la vida.

Desde esta determinación del acrecentamiento la voluntad de poder es verdaderamente poderosa y puede colonizar la voluntad de verdad: una voluntad de poder poderosa impulsa la vida hacia su superación, esto es, refuerza las condiciones de la existencial verdad dionisiaca. En el hacer afirmativo de la voluntad de poder verdad y poder se solapan, integran e identifican, "porque la vida es cabalmente voluntad de poder", ya que "vivir (algo) es fabular". En virtud de su dominio, la voluntad de verdad hecha voluntad de poder imprime una consistencia y una fijeza intrínsecamente caduca y frágil que, entre la madeja de perspectivas, determinan la filosofía de Nietzsche como una filosofía "limitada": introduce el ser en el devenir, nunca perdiendo de vista que aquel tiene la integridad menesterosa de una ficción. El hombre se adueña de la verdad cuando la domeña y hace de esta una mentira afirmadora de la propia vida; verdad y mentira, mentira y verdad han dejado de ser estamentos contrarios y en natural oposición; son ficciones, interpretaciones insertas en la dinámica perspectivista de la plasticidad de la voluntad de poder.

La voluntad de poder tenía como límite condicionante la alteridad, por lo que en su despliegue entra en íntimo contacto con otras perspectivas, otras verdades con las que se mezcla y domina - ora "fusión de horizontes" ora fagocitándolas-, en el ejercicio de su libertad superadora. En esta capacidad de superación de sí misma a través del conflicto jerárquico con otras voluntades se acaba por desvelar la transvaloración: agotados no solo los contenidos valorativos, sino el marco de posibilidad y de contemplación de la valoración, el núcleo de trascendencia de la voluntad de poder termina por transmutar el propio paradigma valorativo, causando un cataclismo intelectual que Zaratustra apresó en la metáfora del cambio de tablero. El conflicto intelectual que acaba llegando a Zaratustra como un problema de magnitudes colosales, es el del fin del sujeto epistémico, aquel de la tradición bimilenaria platónica del 
"mundo verdadero". El cambio de tablero que exige el sabio persa afecta a las reglas del juego: tiene lugar una transmutación del sustrato epistémico en el nuevo, trágico; y a los jugadores: el sujeto epistémico ha perdido su lugar, el cual está ahora ocupado por el jugador de las reglas trágicas.

En su afirmación de la vida la voluntad de poder asimila e integra otras perspectivas, hasta que una vez colmada, sabiéndose incapaz de continuar su tarea afirmadora desde los contenidos vigentes, se reinventa, a través del sujeto encarnado, en los caracteres de un nuevo horizonte "gramatical" de reglas trágicas.

Zaratustra insiste repetidas veces en la acción de la ruptura, la cual habrá de destrozar las viejas tablas de valor, pues la ruptura y el futuro están coligados y en estricta dependencia; la alteridad solo abre expectativas desde las nuevas tablas de valor que han de asentarse sobre las ruinas de las pretéritas. Así es la lógica dionisiaca del devenir: destrucción y creación. El desprecio ha de destruir todo lo existente para poder, desde el nuevo sustrato virgen, crear. Así la acción de la voluntad de poder no es únicamente creadora y afirmadora, sino re-creadora y re-afirmadora. Esta última actitud es imprescindible para dejar finalmente atrás el nihilismo, para consumarlo y superarlo. Este ha corroído las tablas occidentales hasta disolverlas en su totalidad, luego la única respuesta afirmativa pasará por una regeneración de las condiciones de vida, o sea, de los esquemas de valoración. La cálida luz de las nuevas auroras reverbera en la voluntad de verdad que ha hecho de sí voluntad de poder: la vida como obra de arte es la máxima creación artística de la voluntad de poder, que responde a la posibilidad del sujeto libre, emancipado, "redimido" de los ídolos de la tradición metafísica, ahora vacíos tras haber recibido el golpe del martillo.

\section{FUENTES DE REFERENCIA CONSULTADAS}

Conill, J. (1991). El enigma del animal fantástico. Madrid: Tecnos.

Conill, J. (2007). El poder de la mentira. Madrid: Tecnos.

Deleuze, G. (2013). La filosofía de Nietzsche. Barcelona: Anagrama. 
Fink, E. (1984). La filosofia de Nietzsche. Madrid: Alianza Editorial.

Foucault, M. (2006). Las palabras y las cosas, Madrid: Siglo XXI de España.

Gadamer, H.-G., (2008). Teoría, técnica, práctica. En N. Machain. El estado oculto de la salud. Barcelona: Gedisa.

Gasché, R. (1985). Ecce homo or the Written Body. Oxford Literary Review, $7(1 / 2), 3-24$.

Grondin, J. (2009). ¿Hay que incorporar a Nietzsche a la hermenéutica? Razones de una pequeña resistencia. Estudios Nietzsche (9), 53-66.

Heidegger, M. (2013). Nietzsche. Barcelona: Ariel.

Martínez Becerra, P. (2008). Nietzsche y la hermenéutica orgánica. Veritas, III (19), 331-342.

Nietzsche, F. (2002). Crepúsculo de los ídolos. Madrid: Alianza Editorial.

Nietzsche, F. (2005). Más allá del bien y del mal. Madrid: Alianza Editorial.

Nietzsche, F. (2007a). El Anticristo. Madrid: Alianza Editorial.

Nietzsche, F. (2007b). Sobre verdad y mentira en sentido extramoral. Madrid: Tecnos.

Nietzsche, F. (2008a). Fragmentos póstumos II. Madrid: Tecnos.

Nietzsche, F. (2008b). Fragmentos póstumos IV. Madrid: Tecnos.

Nietzsche, F. (2009). Asi habló Zaratustra. Madrid: Alianza Editorial.

Nietzsche, F. (2010a). Fragmentos póstumos I. Madrid: Tecnos.

Nietzsche, F. (2010b). Fragmentos póstumos III. Madrid: Tecnos.

Nietzsche, F. (2011a). Correspondencia V. Madrid: Trotta.

Nietzsche, F. (2011b). La genealogía de la moral. Madrid: Alianza Editorial.

Nietzsche, F. (2014a). Aurora, en Obras completas III. Madrid: Tecnos.

Nietzsche, F. (2014b). La gaya ciencia. En Obras completas III. Madrid: Tecnos.

Otero León, L. (2008). De la estética como fisiología en Nietzsche a la curación como obra de arte en Gadamer. Revista Internacional de Filosofía (XIII), 19-35.

Platón, (1981). Apología de Sócrates. En Diálogos I. Madrid: Gredos. 
Romero de Solís, D. (1981). Poiesis. Madrid: Taurus.

Santiago Guervós, L.-E. de (2004). Arte y poder. Aproximación a la estética de Nietzsche. Madrid: Trotta.

Wilde, O. (2016). La decadencia de la mentira. Barcelona: Austral. 